\title{
Synergy between Prkdc and Trp53 regulates stem cell proliferation and GI-ARS after irradiation
}

\author{
Kay E Gurley ${ }^{1}$, Amanda K Ashley ${ }^{2}$, Russell D Moser ${ }^{1}$ and Christopher J Kemp ${ }^{*, 1}$
}

lonizing radiation (IR) is one of the most widely used treatments for cancer. However, acute damage to the gastrointestinal tract or gastrointestinal acute radiation syndrome (GI-ARS) is a major dose-limiting side effect, and the mechanisms that underlie this remain unclear. Here we use mouse models to explore the relative roles of DNA repair, apoptosis, and cell cycle arrest in radiation response. IR induces DNA double strand breaks and DNA-PK mutant Prkdc ${ }^{\text {scid/scid }}$ mice are sensitive to GI-ARS due to an inability to repair these breaks. IR also activates the tumor suppressor p53 to trigger apoptotic cell death within intestinal crypt cells and p53 deficient mice are resistant to apoptosis. To determine if DNA-PK and p53 interact to govern radiosensitivity, we compared the response of single and compound mutant mice to $8 \mathrm{~Gy}$ IR. Compound mutant Prkdc $\mathrm{scid}^{\mathrm{sccid}} / \mathrm{Trp} 53^{-/-}$mice died earliest due to severe GI-ARS. While both Prkdc ${ }^{\text {scid/scid }}$ and Prkd $c^{\text {scid/scid }} /$ Trp53 $^{--}$mutant mice had higher levels of IR-induced DNA damage,

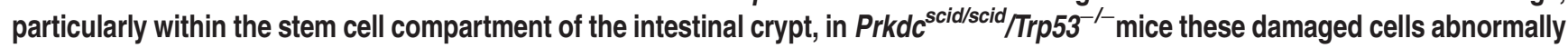
progressed through the cell cycle resulting in mitotic cell death. This led to a loss of Paneth cells and a failure to regenerate the differentiated epithelial cells required for intestinal function. IR-induced apoptosis did not correlate with radiosensitivity. Overall, these data reveal that DNA repair, mediated by DNA-PK, and cell cycle arrest, mediated by $\mathrm{p} 53$, cooperate to protect the stem cell niche after DNA damage, suggesting combination approaches to modulate both pathways may be beneficial to reduce GI-ARS. As many cancers harbor p53 mutations, this also suggests targeting DNA-PK may be effective to enhance sensitivity of p53 mutant tumors to radiation.

Cell Death and Differentiation (2017) 24, 1853-1860; doi:10.1038/cdd.2017.107; published online 7 July 2017

lonizing radiation (IR) causes DNA double strand breaks (DSBs) that can trigger two distinct cellular responses: DNA repair that contributes to cell survival, versus apoptosis or programmed cell death. ${ }^{1}$ What factors regulate the decision to execute one or the other of these two responses within a given cell or between cell types, and how this dictates overall response to IR in vivo is unclear.

DNA DSBs can be repaired by homologous recombination, a pathway that predominates in cells that are in the $S / G_{2}$ phase of the cell cycle or by the nonhomologous end-joining (NHEJ) pathway which predominates in cells in $\mathrm{G}_{0} / \mathrm{G}_{1}{ }^{2}$ Stem cells are typically in $G_{0} / G_{1}$ and so these cells may be especially reliant on NHEJ. ${ }^{3,4}$ To initiate NHEJ, two proteins, Ku70 and Ku80, bind to the broken DNA ends and recruit DNA-PKcs, the catalytic subunit of the DNA-PK holoenzyme, which together with Artemis, XLF, XRCC4 and ligase IV processes and rejoins the breaks. $^{5}$ Severe combined immunodeficient mice (Prkdc ${ }^{\text {scid/scid })}$ have reduced DNA-PKcs activity due to a mutation in Prkdc at Tyr4046, resulting in impaired DNA DSB repair and radiosensitivity. ${ }^{6,7}$ DNA DSBs can also activate p53 leading to upregulation of pro-apoptotic genes and apoptotic cell death. Transit amplifying intestinal crypt cells from $\operatorname{Trp}_{53}{ }^{-1}$ mice are markedly resistant to the early wave of IR-induced apoptosis which peaks at $4 \mathrm{~h}$, highlighting the important role of p53 in this response. ${ }^{8}$ At $24 \mathrm{~h}$ post IR, a delayed wave of cell death occurs in the $\operatorname{Trp}_{53^{-/}}$mice $^{9}$ attributed to increased mitotic catastrophe due to progression of cells with chromosomal damage through the cell cycle. ${ }^{10}$

The gastrointestinal (GI) tract is highly susceptible to the damaging effects of IR, and GI-ARS is a major limiting factor for certain radiotherapy regimens. The intestine is a tissue that exhibits high cellular turnover making it a useful model to study both stem cell biology and the response to IR. ${ }^{11,12}$ Several markers for the identification of the small intestinal stem cell have been reported including Bmi1, HopX, mTert, Lrig1, and Lgr5+. ${ }^{12}$ Only the Lgr5+ stem cells of the GI, also called crypt base columnar cells (CBC), reside at the base of the crypt between the Paneth cells. ${ }^{13}$ The Lgr5 stem cells divide about once per day ${ }^{14}$ to generate the much more rapidly dividing transit amplifying cells located at positions $+4-10$ of the crypt. The transit amplifying cells in turn generate the differentiated cells of the intestine, including Paneth cells, which migrate to the crypt base adjacent to the stem cells, goblet cells and enterocytes, which migrate up the villi and slough off into the intestinal lumen. This renewal cycle of the epithelial cells takes 3-5 days and occurs throughout adult life.

Given the resistance of p53 null mice to IR-induced apoptosis, several groups have studied the role of p53 and apoptosis in GI-ARS. Kamarov et al. demonstrated that at high dose of IR, Trp53 null mice are more susceptible to GI-ARS than wild-type (WT) mice. This susceptibility was attributed to unrestrained proliferation of p53 null crypt cells leading to

\footnotetext{
${ }^{1}$ Division of Human Biology Fred Hutchinson Cancer Research Center, 1100 Fairview Avenue N, Seattle WA 98109, USA and ${ }^{2}$ Department of Chemistry and Biochemistry New Mexico State University, 1780 East University Avenue, Las Cruces, NM 88003, USA

${ }^{*}$ Corresponding author: CJ Kemp, Division of Human Biology, Fred Hutchinson Cancer Research Center, 1100 Fairview Avenue N, Seattle, WA 98109, USA. Tel: +1 206-667-4252; Fax: +1 206-667-5815; E-mail: cjkemp@fhcrc.org

Received 08.12.16; revised 21.4.17; accepted 30.5.17; Edited by M Oren; published online 07.7.17
} 
mitotic cell death. ${ }^{15}$ Kirsch et al. ${ }^{16}$ established that mice with intestinal-specific deletion of p53 were resistant to apoptosis but susceptible to GI-ARS, and concluded that p53 controls GI-ARS in a manner that is independent of apoptosis. In contrast, mice deficient in the p53 regulated pro-apoptotic protein PUMA are resistant to IR-induced intestinal crypt cell apoptosis, are protected from GI-ARS, and survive longer than WT mice. ${ }^{17}$

We previously reported that, although p53 null mice are resistant to apoptosis, intestinal crypt cells from compound

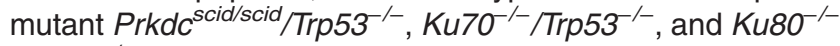
$/ T$ p53 ${ }^{-/}$mice undergo normal WT levels of IR-induced apoptosis, indicating the existence of a p53 independent apoptotic pathway that is active only in the absence of DNAPK. ${ }^{18}$ This unexpected interaction between DNA-PK and p53 in regulating IR-induced apoptosis prompted us to examine the longer-term effects of DNA-PK and p53 on GI-ARS using Prkdc ${ }^{\text {scid/scid }}$ and $\operatorname{Trp}^{53^{-/}}$single and compound mutant mice.

\section{Results}

Prkdc scid/scid $/$ Trp53 $^{-/}$mice are radiosensitive. Adult Prkdc ${ }^{\text {scid/scid }}$, Prkdc $c^{\text {scid/scid }} / \operatorname{Trp} 53^{-/-}, \operatorname{Trp53}{ }^{-1-}$, or WT mice were exposed to a single whole-body dose of 8 Gy IR. WT and $\operatorname{Trp53}^{-/}$mice survived $>10$ days with no signs of distress (Figure 1a). Prkdc ${ }^{\text {scid/scid }} / \operatorname{Trp} 53^{-/-}$mice were the most radiosensitive, with all mice succumbing by day 3 post-

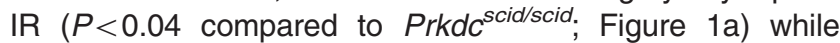
Prkdc ${ }^{\text {scid/scid }}$ mice survived, on average, to day 4 . Both Prkdc ${ }^{\text {scid/scid }}$ and Prkdc $c^{\text {scid/scid } / T r p 53^{-1}}$ mice died from GI-ARS, marked by thinner intestines, shortening of the villi, and extensive disruption of epithelial cell integrity (Figure 1b). In addition to earlier lethality, GI-ARS was more severe in Prkdc $\mathrm{scid}^{\mathrm{scid}} / \mathrm{Trp}_{\mathrm{T}} \mathrm{S}^{-/}$mice, demonstrated by depletion of Paneth cells, absence of crypts, and considerable loss of villi by day 3 . Thus, the absence of p53 did not protect from and instead exacerbated the radiosensitivity of DNA-PKcs mutant mice.

Apoptosis is not the determining factor for GI toxicity. To determine the cellular basis for the GI-ARS of Prkdc $c^{\text {scid/scid/ }}$ $\mathrm{Trp53}^{-/}$compound mutant mice, we examined DNA damage, cell cycle parameters, and cell death at $24 \mathrm{~h}$ post IR. Previous studies indicate that IR-induced apoptosis in the GI crypts from WT, Prkdc ${ }^{\text {scid/scid }}$, and Prkdc ${ }^{\text {scid/scid }} / T r p 53^{-1-}$ mice peaks at $4 \mathrm{~h}$ while $\operatorname{Trp}_{53^{-/}}$mice are resistant to this early wave of apoptosis. ${ }^{8,18}$ Crypt cell apoptosis was low in all genotypes at $24 \mathrm{~h}$ with $<2$ apoptotic figures per crypt. When compared to WT mice, the other genotypes had significantly fewer apoptotic figures (Figure 1c). We next assessed levels of cleaved caspase 3, a marker of caspase-mediated apoptosis. Compared to WT mice, both Prkdc ${ }^{\text {scid/scid }}$ and Prkdc ${ }^{\text {scid/scid }} /$ Trp53 $^{-/}$had significantly fewer caspase 3 positive cells (Figure 1d). Collectively, this indicates that apoptosis in transit amplifying cells of the crypt does not correlate with GI toxicity, as WT mice had the highest levels of apoptosis yet they survived $>10$ days.
Increased DNA damage in the stem cell niche of both Prkdc scid/scid and Prkdc scid/scid $/$ Trp53 $^{-/-}$mice. Persistent DNA damage, measured by $\gamma \mathrm{H} 2 \mathrm{~A}$.X staining at $24 \mathrm{~h}$, was highly dependent on the cellular position within the crypt. In WT and Trp53-1- mice, DNA damage peaked in the transit amplifying zone, at cell positions 4-7 (Figures $2 a$ and b). Few $\gamma \mathrm{H} 2 \mathrm{~A}$.X-positive cells were detected in the stem cell compartment at the base of the crypt or in post mitotic differentiated cells further up the crypt or in the villus. In contrast, in Prkdc ${ }^{\text {scid/scid }}$ and Prkdc ${ }^{\text {scid/scid } / T r p 53^{-1}}$ mice a markedly different distribution of $\gamma \mathrm{H} 2 \mathrm{~A} . \mathrm{X}$ staining was observed, with the highest levels found in cells at the base of the crypt, which progressively decreased as cells moved up the crypts and onto the villi. Further, the number of cells positive for $\gamma \mathrm{H} 2 \mathrm{~A}$.X staining was greater at all cell positions, which would be anticipated in NHEJ deficient cells. Clearly, the greatest impact of DNA-PKcs mutation on DNA damage is seen at the base of the crypt within the stem cell compartment, suggesting these cells are particularly dependent on the NHEJ pathway of DNA repair.

In addition to DNA repair and apoptosis, IR also induces cell cycle arrest, which can affect cell survival. Cell cycle arrest allows time for DNA repair thereby preventing entry of damaged cells into mitosis, which can lead to mitotic cell death. IR-induced DNA damage activates p53, which in turn induces the CDK inhibitor $p 21$, leading to $G_{1}$ cell cycle arrest. Recent studies demonstrate DNA-PK plays a role in RPA32phosphorylation and spindle formation; loss or inhibition of DNA-PK disrupts mitotic progression leading to mitotic catastrophe. ${ }^{19-21}$ We quantified progression into $S$ phase by BrdU incorporation. For all genotypes, BrdU incorporation at $24 \mathrm{~h}$ post-IR was primarily localized to the transit amplifying cells of the crypt (Figure 2c). Trp53 ${ }^{-1}$ mice had the highest number of positive cells per crypt consistent with the known role of p53 in DNA damage induced $\mathrm{G}_{1}$ arrest (Figure $2 \mathrm{~d}$ ).

Increased phospho-H3 staining in the stem cell niche of Prkdc ${ }^{\text {scid/scid } / T r p 53^{-/}}$mice. To discern whether cells were progressing from S phase into mitosis, phospho-H3 (S10) staining was assessed. Both WT and Trp53 ${ }^{-1-}$ mice had a similar distribution of phospho-H3 positive mitotic cells, with a clear peak at positions 4-7 in the transit-amplifying zone of the crypt. Little or no mitotic activity was seen at the base of the crypt in the stem cell compartment or in the upper crypt region and villi (Figure $2 \mathrm{e}$ ). This distribution is similar to that seen in unirradiated mice indicating the spatial organization of proliferation is maintained after IR. By comparison,

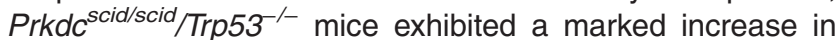
phospho-H3 positive cells throughout the entire crypt, but most notably in cells at the bottom of the crypt (Figure 2e). The average number of cells staining positive for phospho-H3 was significantly higher in both Trp53-/- and

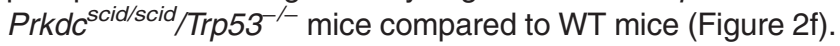
We also noted a significant increase in phospho-H3 levels in

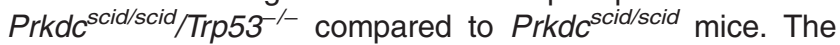
phospho-H3 staining pattern in Prkdc $c^{\text {scid/scid } / T r p 53^{-/}}$mice exhibited prominent nuclear foci indicative of failed mitosis (data not shown). 


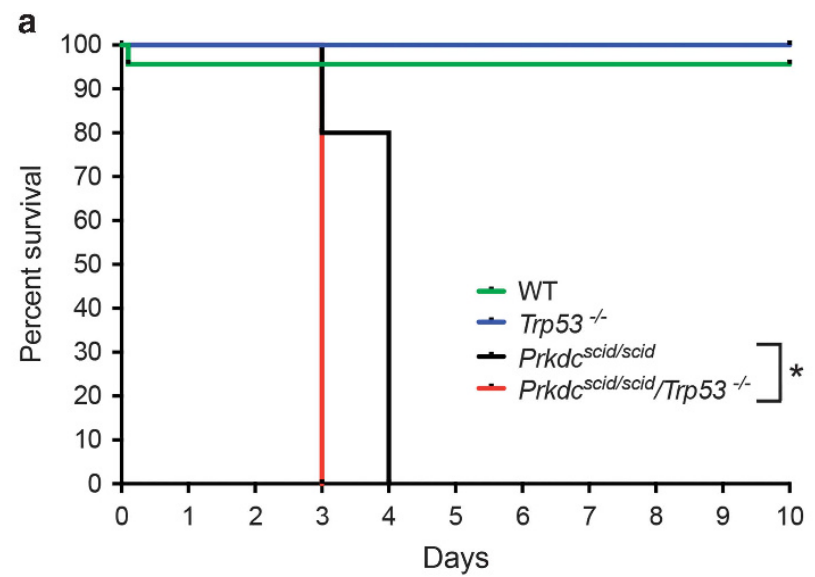

b

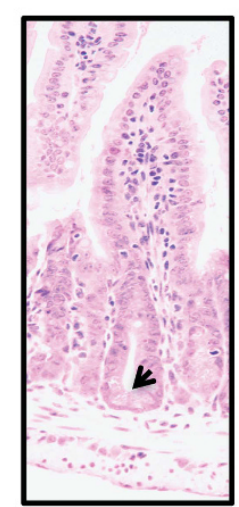

WT

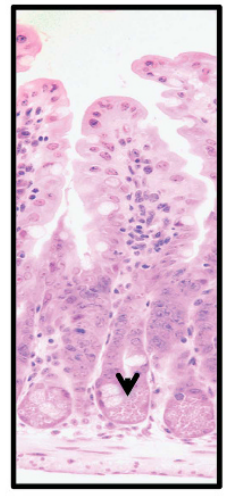

$\operatorname{Trp} 53^{-/}$

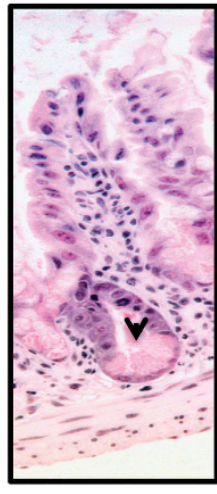

Prkdcscid/scid

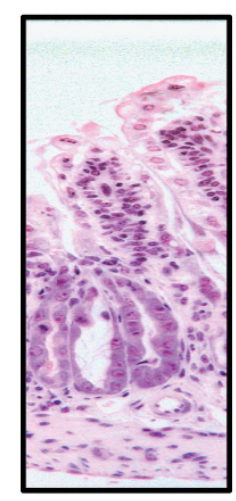

Prkdc scid/scid/Trp53 ${ }^{-1}$
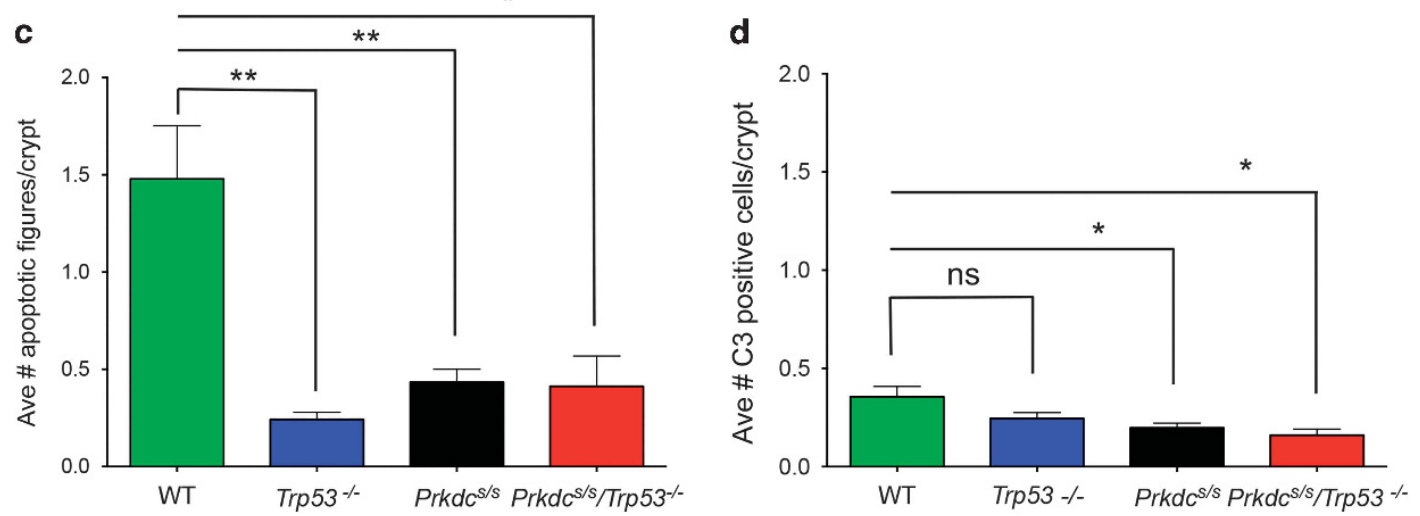

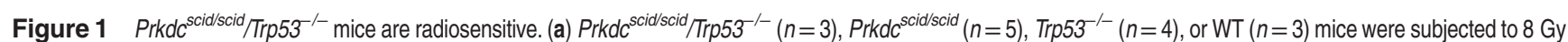
whole body irradiation. Prkdc scid/scid $/ \mathrm{Trp} 53^{-/}$mutant mice died significantly earlier from Gl-ARS compared by Mantel-Cox Log rank test to all other genotypes. WT versus

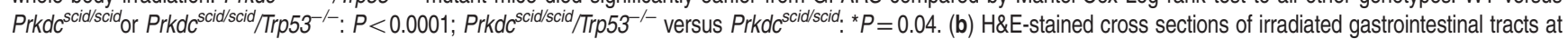
3 days post 8 Gy IR. Note the loss of Paneth cells in the Prkdc scid/scid $/ T r p 53^{-/-}$compared to Prkdc scid/scid mice; arrowheads indicate Paneth cells. (c) Average number of apoptotic figures and caspase 3 (C3) positive cells per crypt $24 \mathrm{~h}$ post 8 Gy IR (Unpaired $t$-test, ${ }^{* \star} P<0.003$; ${ }^{*} P<0.02$ ). (d) Average caspase 3 positive cells per crypt $24 \mathrm{~h}$ post 8 Gy IR (Unpaired $t$ test, ${ }^{*} P<0.02 ; \mathrm{NS}=$ not significant); $P r k d c^{s / s}=P r k d c^{\text {scid/scid }}$

Increased survivin staining in Prkdc $c^{\text {scid/scid } / T r p 53^{-/}}$ mice. Survivin, a member of the inhibitor of apoptosis protein (IAP) family, is upregulated during $\mathrm{G}_{2} / \mathrm{M}$ to control the mitotic spindle checkpoint, and regulate cytokinesis. $^{22}$ It is over-expressed in certain cancers and regulated by $\mathrm{p} 53 .{ }^{23}$ Survivin staining was primarily localized in the transit amplifying cells in WT, Prkdc $c^{\text {scid/scid }}$ and $\operatorname{Trp53}^{-/-}$mice (Figure 3a). In contrast, staining for survivin was more prominent in Prkdc $c^{\text {scid/scid } / T r p 53^{-/}}$mice, and discrete, abundant nuclear foci within the stem cell compartment were evident, consistent with failed cytokinesis (Figure 3a). 
a

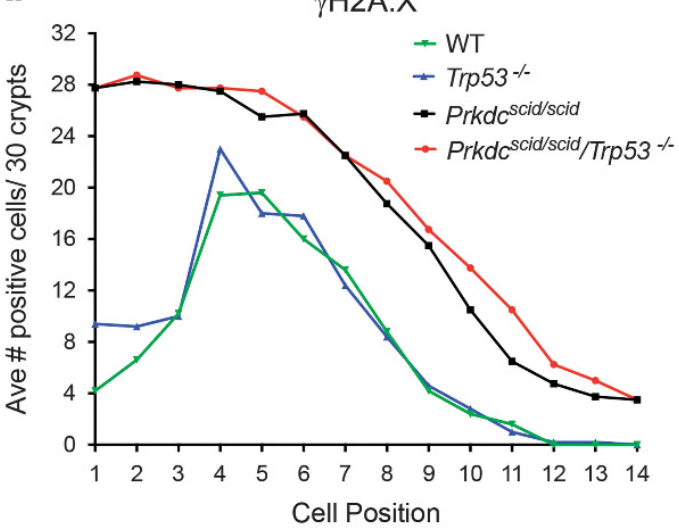

C

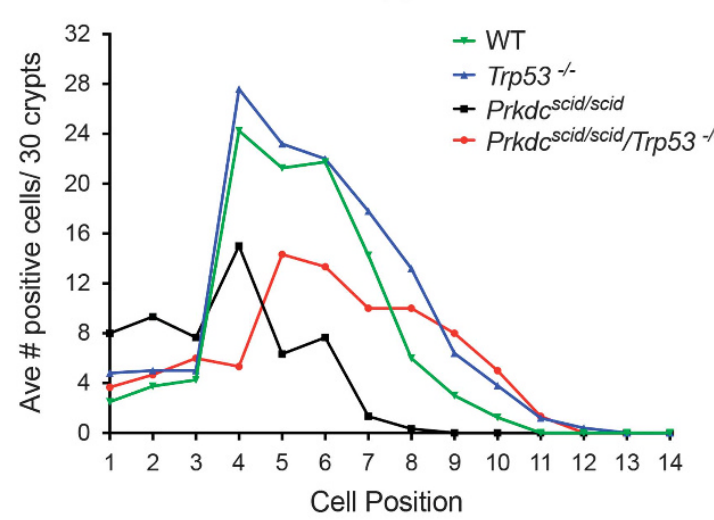

e

$\mathrm{pH} 3(\mathrm{~S} 10)$

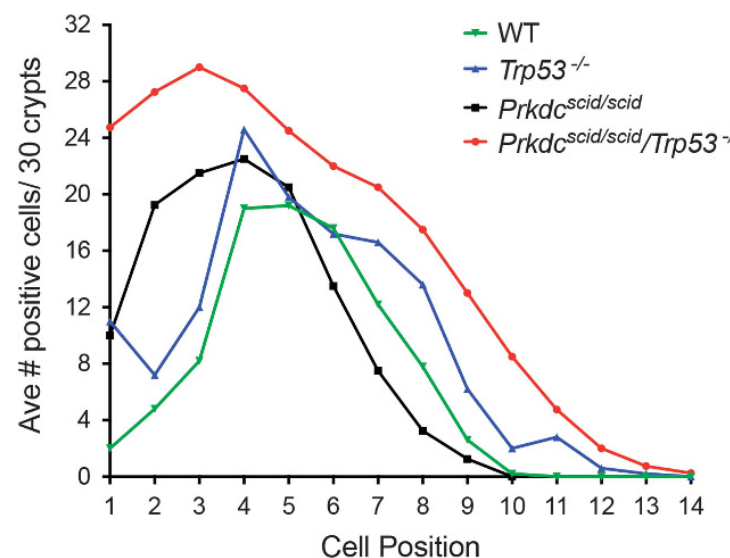

b

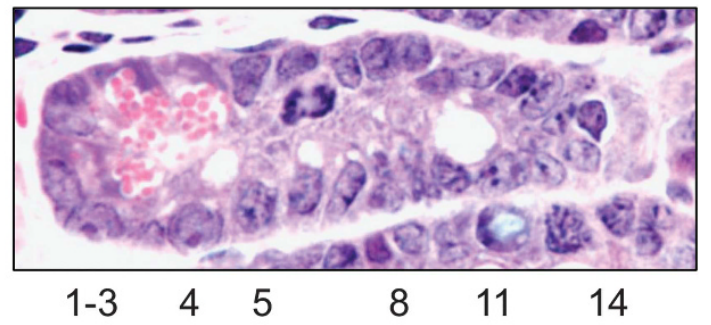

Cell Position d
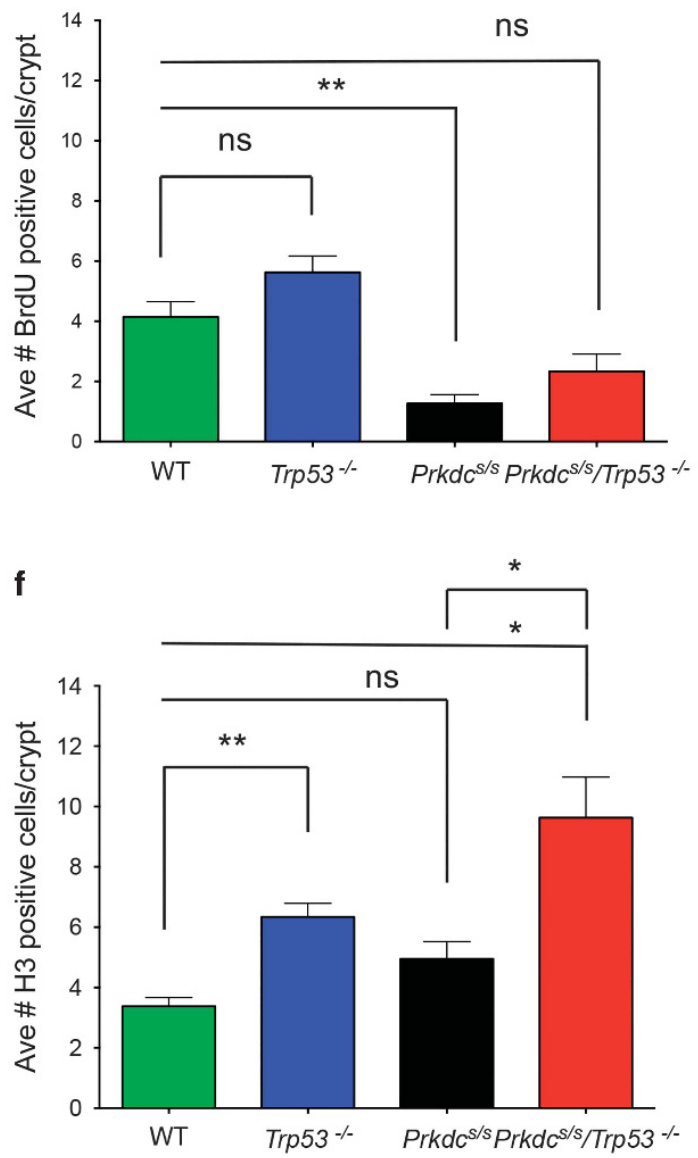

Figure 2 DNA-PK and Trp53 cooperate to prevent aberrant mitotic entry of irradiated intestinal stem cells. (a) Average number of $\gamma$ H2A.X positive cells per crypt position at $24 \mathrm{~h}$ post $8 \mathrm{~Gy}$; Prkdc ${ }^{\text {scid/scid }} / \operatorname{Trp53} 3^{--}(n=4)$, Prkdc $c^{\text {scid/scid }}(n=4)$, Trp53-- $(n=5)$, or WT $(n=5)$. (b) H\&E of crypt showing positional counting. (c) Average number of BrdU-positive cells per crypt position at 24 h post 8 Gy: Prkdc $c^{\text {scidscid }} / \operatorname{Trp} 53^{-/-}(n=3), \operatorname{Prkdc} c^{\text {scidscid }}(n=3), \operatorname{Trp} 53^{-/-}(n=5)$, or WT $(n=4)$. (d) Average number of BrdU positive cells per crypt $24 \mathrm{~h}$ post 8 Gy IR (Unpaired t-test, ${ }^{* *} P<0.007, \mathrm{NS}=$ not significant). (e). Average number of phospho-H3 (S10)-positive cells per crypt position $24 \mathrm{~h}$ post 8 Gy IR:

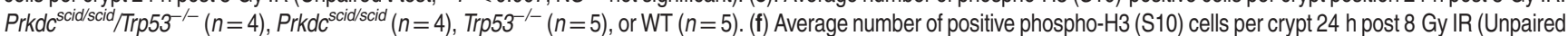
$t$ test, ${ }^{*} P<0.0015$; ${ }^{*} P<0.03$; NS $=$ not significant). Prkdc $c^{s / s}=P r k d c^{\text {scid/scid }}$

Increased mitotic index and abnormal figures in Prkdc ${ }^{\text {scid/scid } / T r p 53^{-/}}$mice. The mitotic index at $24 \mathrm{~h}$ post-IR was significantly higher in $\operatorname{Trp53}^{-/}$and Prkdc ${ }^{\text {scid/ }}$ $\mathrm{scid}^{\mathrm{T}} / \mathrm{Tr}_{\mathrm{S}} \mathrm{3}^{-1}$ mice compared to WT or Prkdc ${ }^{\text {scid/scid }}$ mice (Figure $3 b$ ). A range of abnormalities including failure of chromosomes to align at the metaphase plate, anaphase bridges, lagging chromosomes, chromosome fragments, and tripolar mitotic figures, indicative of mitotic catastrophe were observed in mitotic figures from $\mathrm{Prkdc} \mathrm{scid}^{\mathrm{scid}} / \mathrm{Trp53}{ }^{-/}$mice (Figure $3 \mathrm{c}$ ). The percentage of abnormal mitotic figures was 
a

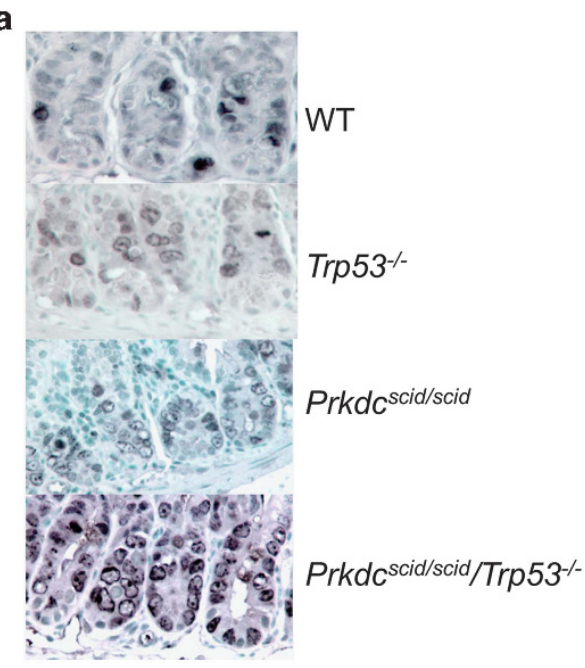

b

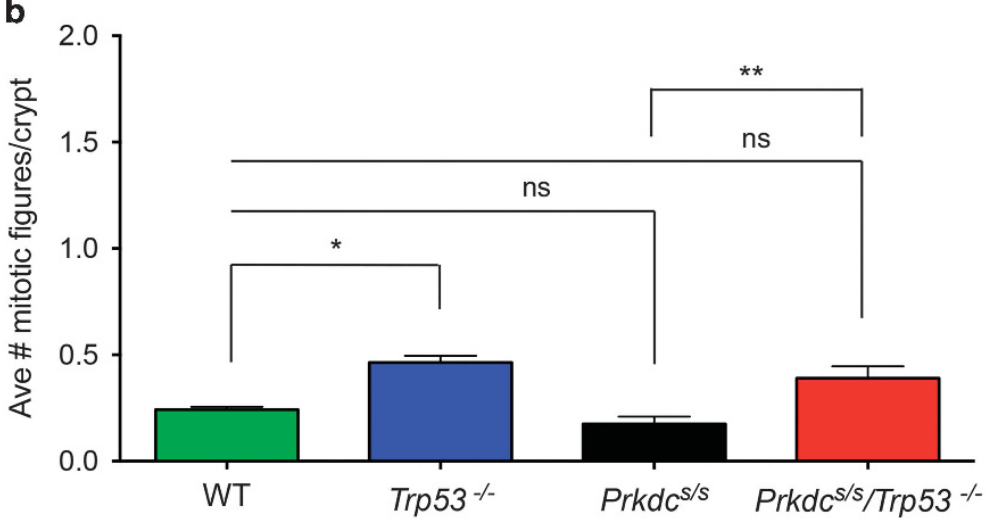

C

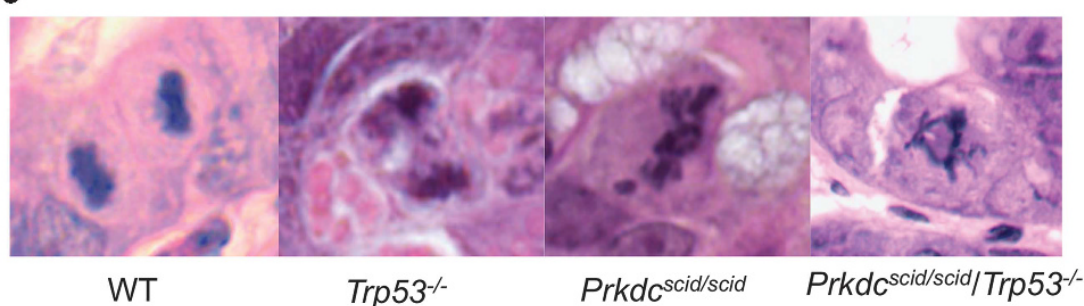

Figure 3 Survivin expression and abnormal mitotic figures. (a) Survivin staining in crypts at $24 \mathrm{~h}$ post 8 Gy. Large positive foci are evident in stem cells of Prkdc ${ }^{\text {scid/scid/ }}$ $\operatorname{Trp53}{ }^{-/}$mice. (b) Average number of mitotic figures per genotype at $24 \mathrm{~h}$ post 8 Gy IR (Unpaired $t$-test, ${ }^{*} P<0.0001 ;{ }^{* *} P<0.008$ ). (c) Representative H\&E stained images of mitotic figures at $24 \mathrm{~h}$ post IR. Prkdc $c^{s / s}=$ Prkdc scid/scid

nearly $100 \%$ in both Prkdc ${ }^{\text {scid/scisd }} /$ Trp53 $^{-/}$and Prkdc ${ }^{\text {scid/scid }}$ mice.

The co-localization of $\gamma \mathrm{H} 2 \mathrm{~A} . \mathrm{X}$, survivin, and phospho-H3 (S10) within the stem cell compartment in irradiated Prkdc ${ }^{\text {scid/scid }} / \operatorname{Trp53}^{-1-}$ mice along with the high number of abnormal mitotic figures indicates that, in the absence of functional DNA-PK and p53, cells with DNA damage abnormally enter $S$ phase and progress to mitosis. The elevated mitotic index and the enhanced phospho-H3 staining highlight the significance of cell proliferation rather than apoptosis as the principal difference between the Prkdc ${ }^{\text {scid/scid } / T r p 53^{-1}}$ and the Prkdc ${ }^{\text {scid/scid }}$ mice.
Depletion of LGR5 stem cells and Paneth cells in Prkdc $^{\text {scid/scid } / T r p 53^{-/}}$mice. We examined Lgr5 stem cell fate using an antibody to the cell surface protein Lgr5 (GPR49). ${ }^{13}$ Lgr5 ${ }^{+}$membrane staining was evident in isolated cells at the crypt base, between the Paneth cells, consistent with the location of these stem cells (Figure 4a). Similar staining was observed prior to and at $24 \mathrm{~h}$ post IR for all genotypes. However, by day 3 post-IR, a marked loss of crypts with few remaining Lgr5 cells was evident in Prkdc ${ }^{\text {scid/scid }} /$ Trp53 $^{-1-}$ mice (Figures $1 \mathrm{~b}$ and $4 \mathrm{a}$ ). In the few crypts that remained in Prkdc ${ }^{\text {scid/scid }} / \operatorname{Trp} 53^{-1}$ mice, cells at the base stained positive for $\gamma \mathrm{H} 2 \mathrm{~A} . \mathrm{X}$ and $\mathrm{BrdU}$, indicating 
a

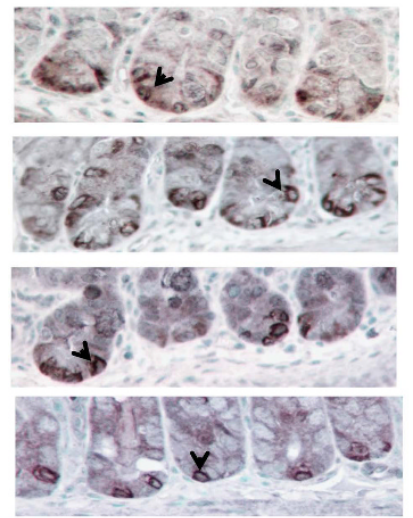

b

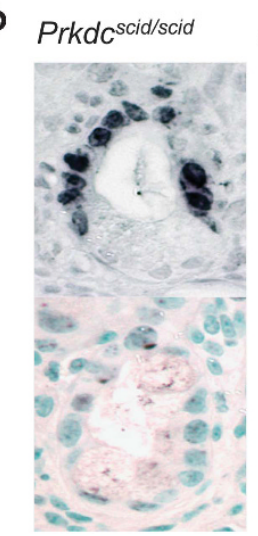

d 3

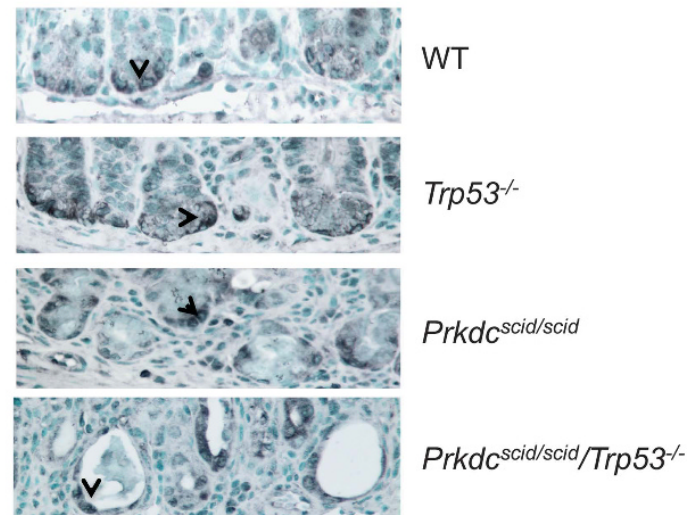

Prkdc scid/scid/Trp53--

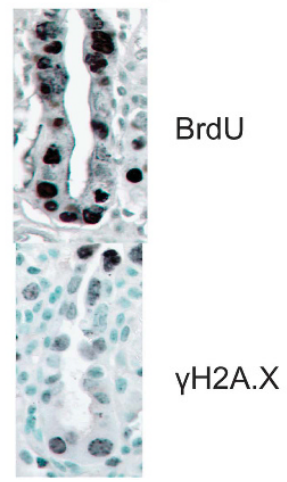

Figure 4 Lgr5 expression in irradiated crypts. (a) GPR49 (Lgr5) staining of crypts $24 \mathrm{~h}$ or 3 days after 8 Gy IR. Positive cells remain at all time points. (b) BrdU and $\gamma \mathrm{H} 2 \mathrm{~A}$.X staining of a remaining d 3 crypt from Prkdc $c^{\text {scid/scid }}$ or Prkdc ${ }^{\text {scidsscid } / T r p 53^{--}}$mice Note more $\gamma \mathrm{H} 2 \mathrm{~A}$.X and BrdU staining in the crypt base of the Prkdc $c^{\text {sid/scid }} / \mathrm{Tr}_{\mathrm{r}} 53^{-/-}$mouse

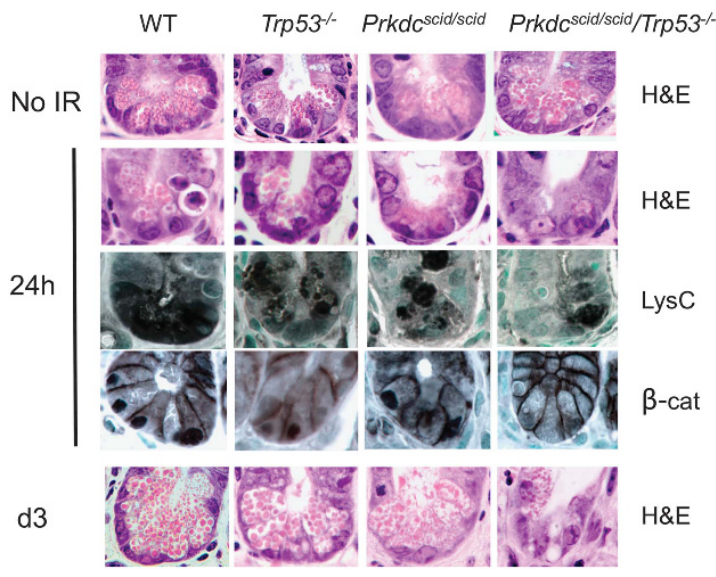

Figure 5 Loss of Paneth cells in crypts of irradiated Prkdc scid/scid $/ T r p 53^{-/-}$mice. H\&E and lysozyme $\mathrm{C}$ staining of secretory granules showing loss of Paneth cells in Prkdc $c^{\text {scid/scid }} / \mathrm{Tr} 53^{-/}$mice. Note reduced nuclear $\beta$-catenin staining in Paneth cells of Prkdc scidscid $/ \mathrm{Trp}^{-1 /-}$ mice

stem cells with unresolved DNA damage were entering into the cell cycle (Figure 4b).

Another feature of Gl-ARS that was unique to Prkdc scid/scid/ $\operatorname{Trp53}^{-1}$ mice was the loss of Paneth cells, evident in H\&E staining at both 24 and $72 \mathrm{~h}$ post IR (Figures $1 \mathrm{~b}$ and 5). Paneth cells contain abundant lysozyme $\mathrm{C}$ within secretory granules, and staining for lysozyme $\mathrm{C}$ was reduced in Prkdc scid/scid,
$\operatorname{Trp53}^{-/}$mice. Paneth cells are important for maintenance and pluripotency of the stem cells, as well as the ability of stem cells to regenerate functional daughter cells after injury. ${ }^{24,25}$ As Wnt/B-catenin signaling is important for Paneth cell differentiation $^{26}$ and can be down-regulated by activated p53, ${ }^{27}$ we examined $B$-catenin staining in irradiated tissues. Nuclear B-catenin, evidence of active Wnt signaling, was seen in Paneth cells from WT, Trp53-/- and Prkdc ${ }^{\text {scid/scid mice }}$ (Figure 5). However, little or no nuclear B-catenin was observed in the few remaining Paneth cells of the Prkdc ${ }^{\text {scid/scid/ }}$ Trp53 ${ }^{-/}$mice, suggesting that their loss could be due to deregulated Wnt signaling.

ATM $^{-/} /$Trp53 $^{-1-}$ mice have a different GI-ARS phenotype. Ataxia-telangiectasia mutated (ATM) is needed for the initiation of double-strand break repair by homologous recombination (HR). Westphal et al. ${ }^{28}$ illustrated the additional loss of p53 in ATM null mice did not alter survival after irradiation, though $A T M^{-1}$ mice induce apoptosis similarly to WT while $A T M^{-1} / \operatorname{Trp}^{-1-}$ mutants are markedly resistant to apoptosis. ${ }^{18,29}$ To examine the relative role of $\mathrm{NHEJ}$ versus $\mathrm{HR}$ in IR response, we compared $\gamma \mathrm{H} 2 \mathrm{~A}$.X staining between DNA-PK and ATM deficient crypt cells after 8 Gy IR. ATM ${ }^{-1}$ mice had a $\gamma \mathrm{H} 2 \mathrm{~A} . \mathrm{X}$ distribution similar to WT mice, while a sixfold increase in $\gamma \mathrm{H} 2 \mathrm{~A} . \mathrm{X}$ positive cells in the stem cell compartment of the crypt was evident in Prkdc ${ }^{\text {scid/scid }}$ mutant mice (Figure 6). The $A T M^{-1} / \operatorname{Trp}^{-1-}$ mice also retained their 
a

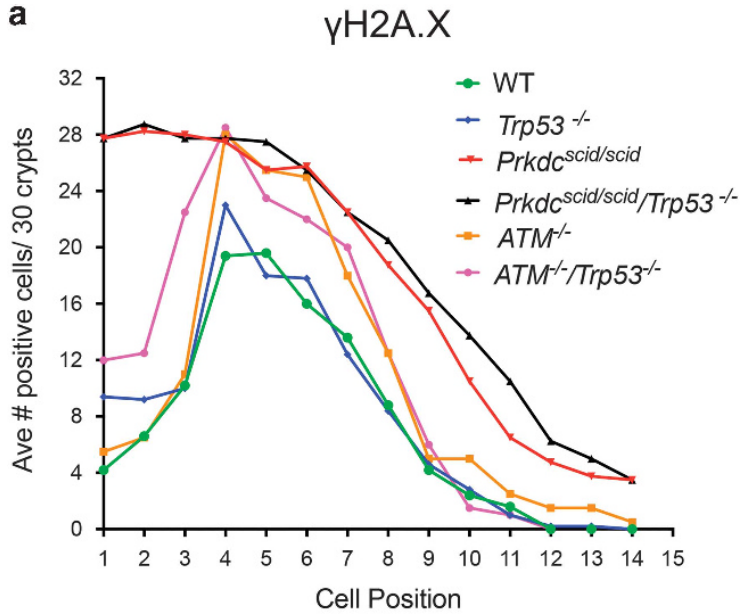

b

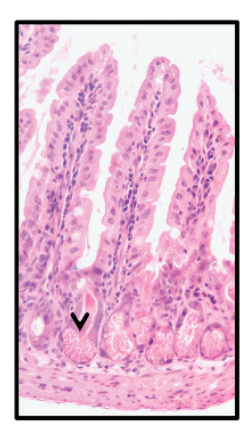

d3

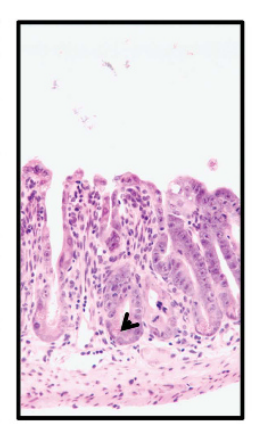

d4
Figure $6 \mathrm{ATM}^{-1} / \mathrm{Trp53^{-1 }}$ mice are radiosensitive, but have a different phenotype compared to Prkdc scid/scid $/ \mathrm{Tr} p 53^{-/-}$mice. (a) Positional counts of $\gamma \mathrm{H} 2 \mathrm{~A}$. $\mathrm{X}$ positive cells $24 \mathrm{~h}$ after $8 \mathrm{~Gy} ; \operatorname{ATM}^{-1}(n=2), \operatorname{ATM}^{-1} / \operatorname{Trp}^{-1-}(n=2)$. Data from other genotypes are replotted here from Figure 2. (b) H\&E staining of $A T M^{-1-}$ / $p 53^{-/-}$mouse at day 3 left, and day 4 right. Note evidence of Paneth cells at both time points (arrowheads)

Paneth cells, observable in the Gl crypts at d 3 and d 4 post-IR. This demonstrates the NHEJ pathway of DSB repair is predominant in Lgr5 cells.

\section{Discussion}

These studies reveal a functional interaction exists between DNA-PK and p53 within the stem cell compartment that governs GI-ARS. While DNA-PK mutant mice are radiosensitive, simultaneous loss of p53 exacerbated the radiosensitivity, characterized by loss of crypts and Paneth cells, absence of villi, intestinal collapse and earlier lethality. Reduced DNA-PK activity leads to persistent DNA damage, most notably in the stem cell compartment, and this coupled with loss of p53-mediated cell cycle arrest, results in aberrant progression of damaged cells into mitosis and ensuing mitotic catastrophe. In agreement with previous studies, p53 dependent apoptosis in transit amplifying cells did not correlate with GI-ARS. ${ }^{15,16,28}$ Rather, the cell cycle arrest function of p53, especially in the context of excessive DNA damage, affects the overall tissue response to IR damage. ${ }^{30}$ PUMA knockout mice are resistant to apoptosis and protected from succumbing to early GI-ARS at high doses of IR; notably, the mice did eventually die from Gl-ARS, albeit several days after WT. ${ }^{17}$ This is indicative that it is not only the initial apoptotic response that is important to GI-ARS, but also later cellular repair and mitotic integrity.

Stem cells need to persist throughout the life of the organism to maintain and regenerate damaged tissues, and so must have robust mechanisms to ensure their survival and to maintain genomic integrity. Paneth cells produce factors critical for maintaining gastrointestinal stem cells in their quiescent state; selective depletion of Paneth cells in mouse models leads to loss of stem cells. ${ }^{24}$ Lgr5+ stem cells are required for IR-induced intestinal regeneration, and Lgr5 +-depleted mice are highly radiosensitive. ${ }^{31}$ Loss of crypt Paneth cells was already apparent by $24 \mathrm{~h}$ post IR in the Prkdc ${ }^{\text {scid/scid } / T r p 53^{-1}}$ mice, indicating failure to produce or maintain these differentiated cells, and by day 3 , crypts were

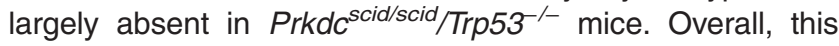
leads to failure to maintain functional crypts and differentiated intestinal epithelial cells, highlighting the importance of DNA-PK in maintaining crypt homeostasis.

We also noted a marked increase in persistent DNA damage in Prkdc ${ }^{\text {scid/scid }}$ mutant compared to $A T M^{-1}$ or WT mice, particularly within the stem cell compartment at the base of crypt. Overall, this indicates these cells are especially reliant on DNA-PK mediated DNA DSB repair, consistent with NHEJ as the primary DNA DSB repair pathway in $\mathrm{G}_{0} / \mathrm{G}_{1}$ cells. Other studies demonstrated increased DNA repair activity in stem cells, which may serve to protect these long-lived cells from endogenous and environmental DNA damage.,32,33

In addition to its well-known DNA repair function, DNA-PK also plays a role in mitotic spindle formation and mitotic progression. ${ }^{21}$ Inhibition or depletion of DNA-PK leads to chromosome misalignment, multipolar spindles and polyploidy. ${ }^{20,34}$ Cells lacking DNA-PKcs have defective replication checkpoint arrest and sustained H2A.X phosphorylation that persists in cells entering mitosis, indicating inappropriate mitotic entry with unrepaired damage, ${ }^{19,35}$ which likely contributes to the GI-ARS phenotype observed.

The radiosensitive phenotype of DNA-PK mutant cells exacerbated by $\mathrm{p} 53$ loss is indicative of a functional interaction between DNA-PK and p53. In addition to an increase in persistent DNA damage in the stem cell compartment, irradiated $\mathrm{PrkdC} \mathrm{c}^{\text {scid/scid } / T r p 53^{-/}}$mice abnormally progress through the cell cycle, apparent by increased BrdU incorporation, phospho-H3 staining, and abnormal mitotic figures. While reduced DNA-PK activity leads to persistent DNA damage, this coupled with loss of p53 mediated cell cycle arrest results in aberrant progression of damaged cells into mitosis and ensuing mitotic catastrophe, effectively depleting the stem and Paneth cells, eventually leading to tissue failure.

These results highlight the importance of both in vivo cellular hierarchies and genetic interactions in dictating overall tissue response to DNA damaging agents such as IR. The functional interaction between DNA-PK and p53 that affects stem cell fate after damage may be useful in designing treatments for GI-ARS and p53 mutant cancers. 
Materials and Methods

Mice. C57BL/6 (Prkdc ${ }^{\text {scid/scid }}$ ) mice (Jackson Laboratory, Bar Harbor, ME, USA) were crossed with C57BL/6 Trp53 knockout mice ${ }^{36}$ to generate single and compound mutant mice and WT littermate controls. Generation of $A T M^{-1} / / \mathrm{Trp} 53^{-1}$ mice was as previously described. ${ }^{29}$ Genotyping was done using established protocols available on request. All mice were kept in microisolator cages. Adult mice received a single dose of $8 \mathrm{~Gy}$ from a Mark I Cesium irradiator. Mice were killed at $24 \mathrm{~h}$ or when they became moribund. Some mice were injected with BrdU (100 mg/kg i.p., Sigma Aldrich, St. Louis, MO, USA) $1 \mathrm{~h}$ before sacrifice. All procedures were approved by the Fred Hutchinson Cancer Research Center Institutional Animal Care and Use Committee.

Immunohistochemistry. Tissues were fixed in neutral buffered formalin, and then processed to paraffin. Sections $(4 \mu \mathrm{m})$ were deparaffinized and rehydrated and stained with hematoxylin and eosin (H\&E), or subjected to immunohistochemistry for specific proteins or BrdU using a three step $A B C$ technique with the following pre-treatments. Sections stained for phosphorylated histone H3 (S10; Cell Signaling Technology, Danvers, MA, USA), phosphorylated H2A.X (S139; Cell Signaling Technology), cleaved caspase 3 (Asp175; Cell Signaling), lysozyme (Abcam, Cambridge, MA, USA), $\beta$-catenin (NeoMarkers, Fremont, CA, USA), GPR49 (Lgr5; Abbiotec, San Diego, CA) or survivin (Cell Signaling Technology) were steamed for $20 \mathrm{~min}$ in pH 6.0 citrate buffer. Sections stained for BrdU (Dako, Carpinteria, CA, USA) were treated with $\mathrm{HCl}$ and trypsin. All sections were blocked for peroxidase with $3 \% \mathrm{H}_{2} \mathrm{O}_{2}$, stained with the primary antibody followed by a biotinylated secondary antibody (Vector, Southern Biotech) and streptavidin ABC (Vector Laboratories, Burlingame, CA, USA). Slides were developed using $\mathrm{DAB} / \mathrm{NiC}$ (Sigma-Aldrich, Saint Louis, MO, USA) and counterstained with methylgreen (Sigma-Aldrich).

Quantification. Ten $\times 40$ fields were analyzed and positively stained cells were counted and expressed as positive cells per crypt. For cell position counts, 30 crypts from four to five mice were counted and results shown as the average number of positive cells per cell position.

Statistics. Survival curves were compared using log rank (Mantel-Cox) test. Samples were compared via unpaired, two-tailed Student's $t$ tests using GraphPad Prism software version 6 (San Diego, CA, USA). When variances significantly differed, Welch's correction was used.

\section{Conflict of Interest}

The authors declare no conflict of interest.

Acknowledgements. This work was funded by $\mathrm{NCl}$ grants U01 CA176303, U54CA132383 and U54 CA132381.

1. Roos WP, Thomas AD, Kaina B. DNA damage and the balance between survival and death in cancer biology. Nat Rev Cancer 2016; 16: 20-33.

2. Chapman JR, Taylor MR, Boulton SJ. Playing the end game: DNA double-strand break repair pathway choice. Mol Cell 2012; 47: 497-510.

3. Nijnik A, Woodbine L, Marchetti C, Dawson S, Lambe T, Liu C et al. DNA repair is limiting for haematopoietic stem cells during ageing. Nature 2007; 447: 686-690.

4. Mandal PK, Blanpain C, Rossi DJ. DNA damage response in adult stem cells: pathways and consequences. Nat Rev Mol Cell Biol 2011; 12: 198-202.

5. Radhakrishnan SK, Jette N, Lees-Miller SP. Non-homologous end joining: emerging themes and unanswered questions. DNA Repair (Amst) 2014; 17: 2-8.

6. Biedermann KA, Sun JR, Giaccia AJ, Tosto LM, Brown JM. Scid mutation in mice confers hypersensitivity to ionizing radiation and a deficiency in DNA double-strand break repair. Proc Natl Acad Sci USA 1991; 88: 1394-1397.

7. Danska JS, Holland DP, Mariathasan S, Williiams KM, Guidos CJ. Biochemical and genetic defects in the DNA-dependent protein kinase in murine scid lymphocytes. Mol Cell Biol 1996; 16: $5507-5517$.

8. Merritt AJ, Potten CS, Kemp CJ, Hickman JA, Lane DP, Hall PA. The role of spontaneous and radiation-induced apoptosis in the gastrointestinal tract of normal and p53 deficient mice. Cancer Res 1994; 54: 614-617.
9. Merritt AJ, Allen TD, Potten CS, Hickman JA. Apoptosis in small intestinal epithelial from p53-null mice: evidence for a delayed, p53-independent G2/M-associated cell death after gamma-irradiation. Oncogene 1997; 14: 2759-2766.

10. Bouffler SD, Kemp CJ, Balmain A, Cox R. Spontaneous and ionizing radiation-induced chromosomal abnormalities in p53-deficient mice. Cancer Res 1995; 55: 3883-3889.

11. Potten CS. Radiation, the ideal cytotoxic agent for studying the cell biology of tissues such as the small intestine. Radiat Res 2004; 161: 123-136.

12. Barker N, van Oudenaarden $A$, Clevers $H$. Identifying the stem cell of the intestinal crypt: strategies and pitfalls. Cell Stem Cell 2012; 11: 452-460.

13. Barker N, van Es JH, Kuipers J, Kujala P, van den Born M, Cozijnsen M et al. Identification of stem cells in small intestine and colon by marker gene Lgr5. Nature 2007; 449: 1003-1007.

14. Cheng $\mathrm{H}$, Leblond $\mathrm{CP}$. Origin, differentiation and renewal of the four main epithelial cell types in the mouse small intestine. V. Unitarian Theory of the origin of the four epithelial cell types. Am J Anat 1974; 141: 537-561.

15. Komarova EA, Kondratov RV, Wang K, Christov K, Golovkina TV, Goldblum JR et al. Dual effect of $p 53$ on radiation sensitivity in vivo: $p 53$ promotes hematopoietic injury, but protects from gastro-intestinal syndrome in mice. Oncogene 2004; 23: 3265-3271.

16. Kirsch DG, Santiago PM, di TE, Sullivan JM, Hou WS, Dayton T et al. p53 controls radiationinduced gastrointestinal syndrome in mice independent of apoptosis. Science 2010; 327: 593-596.

17. Qiu W, Carson-Walter EB, Liu H, Epperly M, Greenberger JS, Zambetti GP et al. PUMA regulates intestinal progenitor cell radiosensitivity and gastrointestinal syndrome. Cell Stem Cell 2008; 2: 576-583

18. Gurley KE, Moser R, Gu Y, Hasty P, Kemp CJ. DNA-PK suppresses a p53-independent apoptotic response to DNA damage. EMBO Rep 2009; 10: 87-93.

19. Ashley AK, Shrivastav M, Nie J, Amerin C, Troksa K, Glanzer JG et al. DNA-PK phosphorylation of RPA32 Ser4/Ser8 regulates replication stress checkpoint activation, fork restart, homologous recombination and mitotic catastrophe. DNA Repair (Amst) 2014; 21: 131-139.

20. Shang ZF, Huang B, Xu QZ, Zhang SM, Fan R, Liu XD et al. Inactivation of DNA-dependent protein kinase leads to spindle disruption and mitotic catastrophe with attenuated checkpoint protein 2 Phosphorylation in response to DNA damage. Cancer Res 2010; 70: 3657-3666.

21. Jette N, Lees-Miller SP. The DNA-dependent protein kinase: a multifunctional protein kinase with roles in DNA double strand break repair and mitosis. Prog Biophys Mol Biol 2015; 117 : 194-205.

22. Li F, Ambrosini G, Chu EY, Plescia J, Tognin S, Marchisio PC et al. Control of apoptosis and mitotic spindle checkpoint by survivin. Nature 1998; 396: 580-584.

23. Jin Y, Wei Y, Xiong L, Yang Y, Wu JR. Differential regulation of survivin by $p 53$ contributes to cell cycle dependent apoptosis. Cell Res 2005; 15: 361-370.

24. Sato T, van Es JH, Snippert HJ, Stange DE, Vries RG, van den Born M et al. Paneth cells constitute the niche for Lgr5 stem cells in intestinal crypts. Nature 2011; 469: 415-418.

25. Parry L, Young M, El MF, Clarke AR. Evidence for a crucial role of paneth cells in mediating the intestinal response to injury. Stem Cells 2013; 31: 776-785.

26. Andreu P, Peignon G, Slomianny C, Taketo MM, Colnot S, Robine S et al. A genetic study of the role of the Wnt/beta-catenin signalling in Paneth cell differentiation. Dev Biol 2008; 324: 288-296.

27. Sadot E, Geiger B, Oren M, Ben-Ze'ev A. Down-regulation of beta-catenin by activated p53. Mol Cell Biol 2001; 21: 6768-6781.

28. Westphal $\mathrm{CH}$, Rowan S, Schmaltz C, Elson A, Fisher DE, Leder P. Atm and p53 cooperate in apoptosis and suppression of tumorigenesis, but not in resistance to acute radiation toxicity. Nat Genet. 1997; 16: 397-401.

29. Gurley KE, Kemp CJ. Atm is not required for p53 induction and apoptosis in irradiated epithelial tissues. Mol Cancer Res 2007; 5: 1312-1318.

30. Wei L, Leibowitz BJ, Wang X, Epperly M, Greenberger J, Zhang L et al. Inhibition of CDK4/6 protects against radiation-induced intestinal injury in mice. J Clin Invest 2016; 126: 4076-4087.

31. Metcalfe C, Kljavin NM, Ybarra R, de Sauvage FJ. Lgr5+ stem cells are indispensable for radiation-induced intestinal regeneration. Cell Stem Cell 2014; 14: 149-159.

32. Seita J, Rossi DJ, Weissman IL. Differential DNA damage response in stem and progenitor cells. Cell Stem Cell 2010; 7: 145-147.

33. Hua G, Thin TH, Feldman R, Haimovitz-Friedman A, Clevers H, Fuks Z et al. Crypt base columnar stem cells in small intestines of mice are radioresistant. Gastroenterology 2012; 143: $1266-1276$

34. Lee KJ, Lin YF, Chou HY, Yajima H, Fattah KR, Lee SC et al. Involvement of DNA-dependent protein kinase in normal cell cycle progression through mitosis. J Biol Chem 2011; 286: 12796-12802.

35. Liu S, Opiyo SO, Manthey K, Glanzer JG, Ashley AK, Amerin C et al. Distinct roles for DNA-PK, ATM and ATR in RPA phosphorylation and checkpoint activation in response to replication stress. Nucleic Acids Res 2012; 40: 10780-10794.

36. Donehower LA, Harvey M, Slagle BL, McArthur MJ, Montgomery CA Jr, Butel JS et al. Mice deficient for p53 are developmentally normal but susceptible to spontaneous tumours. Nature 1992; 356: 215-221. 